\title{
Níveis Crescentes de Suplementação Energética sobre o Desenvolvimento de Novilhos Mantidos em Pastagem Natural na Encosta do Sudeste do Rio Grande do Sul ${ }^{1}$
}

\author{
René Mauricio Patiño Pardo 2 , Vivian Fischer ${ }^{3}$, Maira Balbinotti ${ }^{4}$, Claiton Baes Moreno ${ }^{5}$, \\ Everson Xavier Ferreira ${ }^{6}$, Ricardo Irigon Vinhas ${ }^{7}$, Pedro Lima Monks ${ }^{8}$
}

\begin{abstract}
RESUMO - O experimento foi desenvolvido de 11 de agosto a 15 de novembro de 2000, com a finalidade de avaliar os efeitos de suplementação energética com sorgo moído sobre o desempenho de novilhos de corte em pastejo. Foram utilizados 38 novilhos de 12 a 15 meses de idade, sem raça definida, com 159,97 kg. Os animais foram mantidos em pastejo contínuo, em uma pastagem natural melhorada com Lotus subbiflorus e invadida por Eragrostis planna, Ness. Os tratamentos consistiram de controle (T0), sem suplemento; 0,75\% do peso vivo (T0.75) e 1,5\% do peso vivo (T1.5) de grão de sorgo moído. Os animais foram distribuídos aleatoriamente aos tratamentos, segundo delineamento completamente casualizado. Os efeitos da suplementação sobre o ganho de peso médio diário (GMD) e o incremento de escore de condição corporal (IECC) foram observados no primeiro período, de 11 de agosto a 6 de setembro, e na média geral do experimento, quando foram observadas respostas quadráticas do GMD e IECC aos níveis de suplemento. Não foi observado efeito dos níveis de suplemento sobre o ganho de altura de cernelha e perímetro torácico. A suplementação energética permitiu maiores ganho de peso e incremento de escore de condição corporal nos animais suplementados em relação aos animais controle no período final de inverno, mas não apresentou efeito na primavera.
\end{abstract}

Palavras-chave: altura de cernelha, condição corporal, ganho de peso, grão de sorgo

\section{Increasing Levels of Energy Supplementation on Development of Grazing Steers Kept on a Natural Pasture at the Southeastern Region of Rio Grande do Sul}

\begin{abstract}
The trial was conducted from August $11^{\text {th }}$ to November $15^{\text {th }}$, to evaluate the effects of energetic supplementation with ground sorghum grain on grazing beef steers performance. Thirty eight steers without definite breed, aging 12 to 15 months and weighing 159,97 kg were used. Animals were kept under set stocking on a natural pasture improved with Lotus subbiflorus and invaded with Eragrostis planna, Ness. Treatments consisted of control or without supplement (T0); 0.75\% of mean live weight (T0.75) and $1.5 \%$ of mean live weight (T1.75) of ground sorghum grain. Animals were randomly assigned to treatments according to a complete randomized design. The effects of treatments on animals live weight daily gain (ADG) and increment of body condition score (IBCS) were just observed at the first period, from August $11^{\text {th }}$ to September $6^{\text {th }}$, and considering the overall mean of the experiment, when a quadratic response was observed. There were no supplementation effects upon increment of height at withers and hearth girth. Supplementation with ground sorghum grain increased ADG and IBCS compared to no supplemented animals at the end of the winter, however, there was no effect during spring.
\end{abstract}

Key Words: body condition score, height at withers, sorghum grain, weight gain

\section{Introdução}

No Rio Grande do Sul, as pastagens naturais e artificiais ocupam cerca de 12 milhões de hectares, representando 53\% da área total do estado e mantendo um rebanho bovino de aproximadamente $14 \mathrm{mi}-$ lhões, dos quais 1,5 milhões são novilhos de 1 a 2 anos
(IBGE, 1998). Cerca de $80 \%$ do rebanho total bovino e 7 milhões de ovinos são mantidos em pastagens naturais (Mohrdieck, 1980).

A variação sazonal qualitativa e quantitativa das pastagens do Rio Grande do Sul é reconhecida há vários anos. Como causa disto, pode-se citar a sua composição botânica (Jacques et al., 1995). A predo-

\footnotetext{
${ }^{1}$ Pesquisa financiada pela FAPERGS, PPGZ-UFPEL e Parceria agropecuária Piratini.

2 Zootecnista, Mestre em Produção animal pela PPGZ-UFPEL, residente na Colômbia. E.mail: re_patino@yahoo.com

${ }^{3}$ D.S. Produção Animal, Professor adjunto Departamento de Zootecnia UFPEL, Bolsista do CNPq, Pelotas - RS - CEP: $96010-970$. E.mail: vfried@portoweb.com.br; vfried@ufpel.tche.br

${ }^{4}$ Aluno curso de doutorado PPGZ - UFPEL. E.mail: mairab22@ufpel.tche.br

${ }^{5}$ Aluno do curso de medicina veterinária, bolsista de Iniciação Científica FAPERGS.

${ }^{6}$ Aluno do curso de medicina veterinária, bolsista de Iniciação Científica CNPq.

7 Produtor rural, Parceria agropecuária Piratini, Pelotas, RS.

${ }^{8}$ D.S., Produção Vegetal, Professor Adjunto DZ - FAEM - UFPEL. E.mail: plmonks@ufpel.tche.br
} 
minância de espécies estivais, que diminuem drasticamente a velocidade de crescimento abaixo de $15^{\circ} \mathrm{C}$, é uma das causas da redução da oferta de forragem durante o outono e inverno. Além disso, durante a estação quente, ocorrem períodos variáveis de estiagem, que diminuem a produção forrageira. A oferta de matéria seca e a qualidade dos campos naturais podem variar mesmo durante a estação de crescimento (Abdalla et al., 1988), o que pode ser comprovado pela distribuição muito irregular do ganho de peso dos animais durante os meses de primavera-verão (Moojen, 1991; Correa, 1993). No Rio Grande do Sul, em áreas de pastagens nativas de boa qualidade, os ganhos de peso ao longo do ano não são expressivos, em conseqüência das perdas ocorridas no inverno, que chegam a $50 \%$ do ganho obtido no período favorável. Jacques (1999) citou alguns estudos no Rio Grande do Sul, realizados na primavera-verão e início de outono, em pastagem natural sem uso de insumos, em que foram obtidos ganhos de peso de $0,5 \mathrm{~kg} /$ dia e $145 \mathrm{~kg} / \mathrm{ha}$. Estes resultados foram melhorados com a introdução trevo e suplementação durante o período frio (16 de junho a 30 de setembro), quando foram obtidos ganhos diários de $0,583 \mathrm{~kg}$ por animal.

Estas variações cíclicas de peso ao longo do ano afetam negativamente a produtividade animal e a rentabilidade destes sistemas. Assim, para manter um compromisso aceitável entre a produção individual e o rendimento por unidade de área, dispõe-se de varias estratégias, dentre elas, a suplementação com o objetivo de maximizar o consumo e digestibilidade da forragem disponível (Reis et al., 1999). A sua adoção por produtores tem sido crescente, principalmente devido à relação favorável do preço carne/ grão e à facilidade de implantação (Rocha, 1999). O fornecimento de níveis moderados de energia a animais em pastejo poderia ter particular importância para minimizar o efeito das flutuações na oferta forrageira durante o ano. Deve-se, contudo, considerar as possíveis interações negativas do amido sobre a digestibilidade da fibra, especialmente quando fornecidos níveis de grão maiores que $1 \%$ do peso vivo (Horn et al., 1995). Os suplementos podem aumentar a produção animal devido à melhor utilização da pastagem, provendo nutrientes adicionais. A suplementação de maiores quantidades de energia digestível pode permitir taxas mais altas de lotação e elevar a produção por área (Boin \& Tedeschi, 1996; Rocha, 1999).
O objetivo deste trabalho foi avaliar o efeito da suplementação com níveis crescentes de sorgo moído sobre o desempenho produtivo de novilhos de corte em crescimento, mantidos numa pastagem natural melhorada com cornichão (Lotus subbiflorus) e invadida por capim-anonni 2 (Eragrostis planna, Ness).

\section{Material e Métodos}

\section{Procedimento experimental}

O experimento foi desenvolvido na Fazenda São José, propriedade da Parceria Agropecuária Piratini, situada no município de Cerrito, sudoeste do Rio Grande do Sul, no período de 11 de agosto a 15 de novembro de 2000. O experimento consistiu de três períodos experimentais, com duração 27, 35 e 33 dias, correspondendo a primeiro, segundo e terceiro períodos respectivamente. A área total do experimento foi de aproximadamente 17,5 hectares, dividida em três potreiros de 5,8, 5,7 e 6,3 ha.

Os valores médios mensais de temperatura e precipitação, durante a fase experimental, foram de $15,3^{\circ} \mathrm{C}$ e $168 \mathrm{~mm}$. Os dados meteorológicos médios de cada período experimental encontram-se na Tabela 1.

Foram utilizados 38 novilhos de corte não castrados, sem raça definida, provenientes de cruzamentos entre raças européias Hereford, Aberdeen Angus e Charolês, com aproximadamente 12 a 15 meses de idade, e peso inicial de 159,97 $\pm 16,24 \mathrm{~kg}$. Estes novilhos foram originários da região de Santa Vitória do Palmar, caracteristicamente sem carrapatos. Na chegada à propriedade, foram pré-imunizados contra a tristeza parasitária, tratados com vitaminas A e E, e desparasitados antes do inicio da fase experimental.

Os animais foram mantidos em uma pastagem natural melhorada com a sobressemeadura de cornichão "El Rincon" (Lotus subbiflorus) realizada

Tabela 1 - Dados de precipitação e temperaturas médi-
as para cada período
Table $1-\begin{aligned} & \text { Values of mean rainfall and temperature for each } \\ & \text { period }\end{aligned}$


na primavera de 1998, e invadida, em grande parte, por capim- annoni 2 (Eragrostis planna, Ness). O solo apresentou-se com $23 \%$ de argila, um $\mathrm{pH}$ de 5,0 e 1,66\% de matéria orgânica, 8,3 ppm de fósforo, 39 ppm de potássio e 38,6 ppm de sódio, 1,03 meq/ $100 \mathrm{~mL}$ de alumínio, 2,1 meq/100 mL de cálcio e 0,77 meq/100 mL de magnésio (Tedesco et al., 1995).

Foi utilizado o pastejo contínuo com lotação variável. Os animais foram manejados em três grupos inicialmente de 13 animais em cada lote, porém um dos animais do T0.75 adoeceu, durante o primeiro período experimental, e foi retirado do experimento. Os dados relativos a este animal não foram considerados nas análises. Destinou-se um potreiro para cada grupo. Os potreiros, localizados um ao lado do outro, apresentaram topografia plana, solo hidromórfico, vegetação de porte baixo constituída, em grande parte, por capim-annoni 2 (Eragrostis planna, Ness), além de grama tapete (Axonopus affinis Chase), grama forquilha (Paspalum notatum Flügge) e grama seda (Cynodon dactylon). Durante a condução do experimento, mantiveram-se resíduo médio de forragem de 5 a $8 \mathrm{~cm}$ de altura, carga animal inicial aproximada de $345,5 \mathrm{~kg} / \mathrm{ha}$ e oferta diária de forragem aproximadamente de $20 \mathrm{~kg}$ de MS por cada $100 \mathrm{~kg}$ de peso vivo. Além dos animais testados, foram utilizados outros três, como reguladores da carga, utilizando-se como critério a manutenção de oferta de forragem semelhantes nos três tratamentos.

Os tratamentos consistiram de controle ou sem suplemento (T0) e de dois níveis de grão de sorgo moído fornecidos em quantidades equivalentes a $0,75 \%$ (T0.75) e $1,5 \%$ do peso vivo (T1.5). Estas quantidades foram determinadas por ocasião das pesagens dos animais, realizadas no início de cada período experimental. A composição química média do grão de sorgo utilizado foi: matéria seca (MS)
94,2\%, cinzas (C) 2,83\%, proteína bruta (PB) $8 \%$, fibra em detergente neutro (FDN) 45\%, fibra em detergente ácido (FDA) 10\%.

O suplemento foi fornecido diariamente às 14:00 horas, colocado em cochos de madeira nos potreiros, com um espaço de $45 \mathrm{~cm}$ por animal. No dia seguinte, os cochos eram limpos e verificadas as sobras antes do novo fornecimento. A partir da última semana do segundo período, os animais suplementados receberam 40 gramas de uréia por cada $100 \mathrm{~kg}$ de peso vivo, devido à reduzida participação do cornichão na pastagem disponível. Os animais tiveram acesso livre ao sal mineral e água.

\section{Atributos medidos nos animais}

As pesagens foram realizadas ao inicio de cada período e no final do experimento, às 08:00 horas, após 14 horas de jejum completo. Nestas oportunidades foi realizada a atribuição de escore de condição corporal. No início do último período experimental e no final do experimento, foram realizadas medições de altura na cernelha e perímetro torácico. A altura na cernelha foi medida com o auxílio da bengala de Thomas e o perímetro torácico com fita métrica. $\mathrm{O}$ escore de condição corporal foi atribuído segundo uma escala de 1 a 5 pontos, em que 1 correspondeu a extremamente magro e 5 a extremamente gordo. Os valores de escore de condição corporal, ao início do experimento, e da altura na cernelha e perímetro torácico, no início do último período experimental, são apresentados na Tabela 2.

Atributos medidos na pastagem

Foi determinada a quantidade de pastagem de cada potreiro ao início e final de cada período. Foi utilizado o método de avaliação visual com padrões de 1 a 5 (Haydock \& Shaw, 1975), onde 1 correspondeu à área de menor disponibilidade de forragem e 5 à de maior. Os cortes destes cinco padrões foram feitos

Tabela 2 - Valores de escore de condição corporal, ao início do experimento, e de altura na cernelha e perímetro torácico, no início do último período experimental.Valores dos respectivos desvios padrões estão em parênteses.

Table 2 - Mean values for body condition score at the beginning of the trial, and for height at withers and heart girth at the beginning of the last experimental period. Standart mean errors are in brackets

\begin{tabular}{lccc}
\hline & \multicolumn{3}{c}{$\begin{array}{c}\text { Tratamentos } \\
\text { Treatments }\end{array}$} \\
\cline { 2 - 4 } & 0 & 0.75 & 1.5 \\
\hline $\begin{array}{l}\text { Escore de condição corporal } \\
\text { Body condition score }\end{array}$ & $2,88(0,97)$ & $2,83(0,10)$ & $2,88(0,09)$ \\
$\begin{array}{l}\text { Altura na cernelha }(\mathrm{cm}) \\
\text { Height at withers }(\mathrm{cm})\end{array}$ & $104,7(1,21)$ & $105,1(1,26)$ & $106,6(1,21)$ \\
$\begin{array}{l}\text { Perímetro torácico }(\mathrm{cm}) \\
\text { Heart girth }(\mathrm{cm})\end{array}$ & $131,0(1,75)$ & $130,4(1,82)$ & $131,6(1,75)$ \\
\hline
\end{tabular}


ao nível do solo com tesouras de esquilar. Utilizou-se um quadrado de $0,25 \mathrm{~m}^{2}$ e foram realizadas entre 50 e 55 observações por potreiro. As amostras obtidas foram secas em estufa com ventilação forçada a $60^{\circ} \mathrm{C}$ por 48 horas e pesadas, determinando assim a percentagem de MS do material para os cálculos posteriores.

A taxa de acúmulo de forragem foi calculada utilizando o método de gaiolas de exclusão de pastejo (Gardner, 1986). Colocaram-se três gaiolas em cada potreiro, e demarcaram-se duas áreas idênticas: uma das áreas foi cortada rente ao chão, usando um círculo de $0,088 \mathrm{~m}^{2}$, onde foi colocada a gaiola, e deixando a outra como ponto de referência para a escolha da nova área para o inicio do seguinte período. Ao final de cada período, a área demarcada dentro da gaiola foi cortada, pesada verde, seca em estufa a $60^{\circ} \mathrm{C}$ e pesada novamente. A taxa de acúmulo de forragem foi calculada dividindo a quantidade média de matéria seca obtida pelo corte nas gaiolas em dois períodos sucessivos pelo número de dias de cada período experimental.

Foram determinadas a proporção de material verde e morto e a composição florística, realizando duas amostragens, no início e na metade de cada período experimental. Foram cortadas entre 35 e 40 sub-amostras por potreiro por vez para formar duas amostras compostas, usando um círculo de $0,088 \mathrm{~m}^{2}$. Destinou-se uma amostra para determinação dos componentes vivo e morto e a outra para determinação de espécies, separando-os manualmente, com a amostra ainda fresca. As amostras foram secas em estufa com ventilação forçada a $60^{\circ} \mathrm{C}$ por 48 horas, pesadas e, posteriormente, realizados os cálculos de percentagens em base seca.

Foi determinada a composição química da pastagem disponível e daquela obtida por simulação de pastejo. Porcentagens de MS, C, matéria orgânica (MO), PB foram determinadas segundo AOAC (1975), as porcentagens de FDN e FDA, segundo metodologia de Goering \& Van Soest, (1970). Análises de digestibilidade in vitro da matéria seca (DIVMS) e da matéria orgânica (DIVMO) para as amostras obtidas através da simulação de pastejo seguiu a metodologia de Tilley \& Terry (1963). Esta avaliação foi realizada com número variável de amostras colhidas manualmente, durante a atividade de pastejo, próximo aos locais pastejados pelos animais. Em cada período experimental, estas amostras foram coletadas durante dois dias, um no final da primeira semana e outro no final da terceira semana.

\section{Delineamento experimental e análise estatística}

Os animais foram distribuídos aleatoriamente aos tratamentos - níveis de sorgo moído (0; 0,75 e 1,50\% do peso vivo) - segundo um delineamento completamente casualizado, onde cada animal representou uma repetição. Em cada período experimental, os atributos do desenvolvimento corporal foram submetidos à análise de regressão, considerando os seus componentes lineares e quadráticos, usando o procedimento REG do SAS (1989). Os valores de probabilidade apresentados referem-se aos dos testes dos parâmetros da regressão de grau mais elevado significativo (Ho:bi=0) e o nível de significância adotado para a rejeição da hipótese de nulidade foi de 0,05.

Os atributos químicos e produtivos das pastagens em cada período experimental foram submetidos à análise descritiva, sendo apresentadas as suas médias e seus erros-padrão.

\section{Resultados e Discussão}

Os valores de disponibilidade inicial e final da pastagem, oferta de pastagem e carga animal são apresentados na Tabela 3.

Apesar de não ter sido possível realizar uma análise da variância dos atributos da pastagem, podese constatar que estes diferiram numericamente de acordo com o período experimental avaliado. No período 1, a quantidade inicial de pastagem existente foi inferior a dos outros períodos (Tabela 3), na qual aproximadamente $48 \%$ correspondeu a material morto (Tabela 4).

Esta quantidade de forragem provavelmente não restringiu o consumo, situando-se acima dos $1000 \mathrm{~kg}$ MS/ha, reportados por Poppi et al. (1987) como limitantes ao consumo, juntamente com a oferta de MS (21,9 kg MS/100 kg PV). No entanto, quando se considera a oferta de matéria seca verde $(10,51 \mathrm{~kg}$ MS/100 kg PV), observou-se que esta se situou abaixo dos valores que permitem a ingestão máxima de forragem, o que de acordo com Moojen (1991) e Correa (1993) variaram entre 12 e 16 kg MS/100 kg PV, para pastagens nativas da Depressão Central do Rio Grande do Sul.

A composição florística também evidencia a menor qualidade da pastagem no primeiro período em relação ao terceiro período, com a progressiva diminuição da porcentagem de material morto, Eragrostis 
Tabela 3 - Disponibilidade de matéria seca inicial (DISPIMS) e final (DISPFMS) da pastagem (kg/ha), taxa de acúmulo de pastagem, (kg/ha/dia) (TXACUM), oferta (kg MS/100 kg de peso vivo/dia) e carga (kg peso vivo/ha). Os erros padrões das médias são apresentados nos parênteses.

Table 3 - Initial herbage mass (IHM), residual herbage mass (RHM) (kg/ha), pasture growth rate (PGR) (kg/ha/day), pasture availability (PA) ( $\mathrm{kg} \mathrm{DM} / 100 \mathrm{~kg} \mathrm{LW/day)}$ and live weight ( $\mathrm{kg} / \mathrm{ha})$. Standart errors of the mean are shown in the brackets

\begin{tabular}{|c|c|c|c|c|c|c|}
\hline \multirow[b]{2}{*}{$\begin{array}{l}\text { Atributos } \\
\text { Attributes }\end{array}$} & \multicolumn{3}{|c|}{$\begin{array}{c}\text { Tratamentos } \\
\text { Treatments }\end{array}$} & \multicolumn{3}{|c|}{$\begin{array}{l}\text { Períodos } \\
\text { Periods }\end{array}$} \\
\hline & 0 & 0,75 & 1,5 & 1 & 2 & 3 \\
\hline DISPIMS & 1602 & 1806 & 2037 & 1389 & 2274 & 1782 \\
\hline IHM & $(97,96)$ & $(437,03)$ & $(284,09)$ & $(147,54)$ & $(250,90)$ & $(216,87)$ \\
\hline DISPFMS & 1802 & 2312 & 2535 & 2274 & 1782 & 2593 \\
\hline RHM & $(212,50)$ & $(298,44)$ & $(234,95)$ & $(250,90)$ & $(216,87)$ & $(232,01)$ \\
\hline TXACUM & 31,8 & 40,2 & 32,9 & 24,7 & 39,4 & 40,9 \\
\hline$P G R$ & $(9,52)$ & $(3,37)$ & $(2,46)$ & $(6,02)$ & $(3,08)$ & $(2,32)$ \\
\hline Oferta & 24,2 & 24,7 & 24,5 & 21,9 & 28,1 & 23,5 \\
\hline$P A$ & $(1,56)$ & $(2,98)$ & $(1,04)$ & $(0,61)$ & $(1,28)$ & $(0,42)$ \\
\hline Carga & 336 & 390 & 394 & 349 & 371 & 400 \\
\hline Live weight & $(10,85)$ & $(15,57)$ & $(18,05)$ & $(14,18)$ & $(19,93)$ & $(21,51)$ \\
\hline
\end{tabular}

1 T0 = controle; T0.75 = 0,75\% do peso vivo de sorgo moído; T1.5 = 1,5\% do peso vivo de sorgo moído

T0 = control; T0.75 $=0.75 \%$ of live weight of ground sorghum grain; T1.5 $=1.5 \%$ of live weight of ground sorghum grain

Tabela 4 - Valores médios da composição florística da pastagem (\%) por tratamento e período. Os erros padrões das médias são apresentados nos parênteses.

Table 4 - Means values of floristic composition pasture (\%) for treatment and period. Standart errors of the mean are shown in the brackets

\begin{tabular}{|c|c|c|c|c|c|c|}
\hline \multirow[b]{2}{*}{$\begin{array}{l}\text { Atributos } \\
\text { Attributes }\end{array}$} & \multicolumn{3}{|c|}{$\begin{array}{c}\text { Tratamentos } 1 \\
\text { Treatments }\end{array}$} & \multicolumn{3}{|c|}{$\begin{array}{l}\text { Períodos } \\
\text { Periods }\end{array}$} \\
\hline & 0 & 0,75 & 1,5 & 1 & 2 & 3 \\
\hline Material morto & 34,56 & 36,56 & 40,28 & 47,88 & 39,23 & 24,29 \\
\hline Dead material & $(5,47)$ & $(7,99)$ & $(7,34)$ & $(1,94)$ & $(2,85)$ & $(1,33)$ \\
\hline Eragrostis plana Ness & $\begin{array}{l}73,19 \\
(1,64)\end{array}$ & $\begin{array}{l}77,87 \\
(3,18)\end{array}$ & $\begin{array}{l}78,81 \\
(4,09)\end{array}$ & $\begin{array}{l}82,61 \\
(3,02)\end{array}$ & $\begin{array}{l}77,95 \\
(2,72)\end{array}$ & $\begin{array}{l}72,56 \\
(0,48)\end{array}$ \\
\hline Cynodon sp & $\begin{array}{c}6,37 \\
(0,67)\end{array}$ & $\begin{array}{c}4,11 \\
(0,66)\end{array}$ & $\begin{array}{l}5,35 \\
(0,62)\end{array}$ & $\begin{array}{c}5,53 \\
(0,13)\end{array}$ & $\begin{array}{c}5,06 \\
(1,32)\end{array}$ & $\begin{array}{c}4,69 \\
(1,03)\end{array}$ \\
\hline $\begin{array}{l}\text { Paspalum sp + } \\
\text { Axonopus sp }\end{array}$ & $\begin{array}{c}8,61 \\
(0,38)\end{array}$ & $\begin{array}{c}6,83 \\
(1,01)\end{array}$ & $\begin{array}{c}6,64 \\
(1,45)\end{array}$ & $\begin{array}{c}5,08 \\
(1,17)\end{array}$ & $\begin{array}{l}7,58 \\
(0,53)\end{array}$ & $\begin{array}{c}7,88 \\
(0,26)\end{array}$ \\
\hline Lotus subbiflorus & $\begin{array}{c}8,93 \\
(0,06)\end{array}$ & $\begin{array}{c}8,24 \\
(2,08)\end{array}$ & $\begin{array}{c}6,04 \\
(2,09)\end{array}$ & $\begin{array}{c}5,71 \\
(1,99)\end{array}$ & $\begin{array}{c}7,53 \\
(0,91)\end{array}$ & $\begin{array}{l}10,44 \\
(0,89)\end{array}$ \\
\hline $\begin{array}{l}\text { Outros } \\
\text { Others }\end{array}$ & $\begin{array}{c}2,90 \\
(1,08)\end{array}$ & $\begin{array}{c}2,94 \\
(0,89)\end{array}$ & $\begin{array}{c}3,16 \\
(1,10)\end{array}$ & $\begin{array}{c}1,02 \\
(0,01)\end{array}$ & $\begin{array}{c}1,89 \\
(0,03)\end{array}$ & $\begin{array}{c}4,43 \\
(0,21)\end{array}$ \\
\hline
\end{tabular}

${ }_{1}$ T0 $=$ controle; T0.75 $=0,75 \%$ do peso vivo de sorgo moído; T1.5 = 1,5\% do peso vivo de sorgo moído.

$T O=$ control; $T 0.75=0.75 \%$ of live weight of ground sorghum grain; $T 1.5=1.5 \%$ of live weight of ground sorghum grain .

planna, e aumento da participação de Paspalum sp. + Axonopus sp. e Lotus subbiflorus (Tabela 4).

Na Tabela 5, são observados os valores da qualidade química da forragem aparentemente consumida (método de simulação de pastejo). As diferenças numéricas foram pequenas entre tratamentos ou períodos. Contudo, destacam-se os menores valores de proteína bruta e de digestibilidade in vitro da matéria seca e orgânica no primeiro período em relação aos demais períodos. A seletividade exercida pelos animais normalmente permite que os mesmos ingiram uma forragem que é botânica e quimicamente distinta da oferecida, o que, de certa maneira, pode diminuir as diferenças entre tratamentos e entre períodos (Stobbs, 1975; Hodgson, 1990; Walker, 1995).

Na Tabela 6, são apresentadas as médias de ganho médio diário (GMD) e incremento de escore corporal (IECC) para os tratamentos em cada período, além das equações de regressão. Os animais não suplementados apresentaram valores inferiores de GMD e IECC comparados aos suplementados durante o período $1 \mathrm{e}$ na média geral do experimento. Durante o período 1, o 
Tabela 5 - Valores referentes às variáveis da qualidade química avaliadas na pastagem por simulação de pastejo, em percentagens de: matéria seca (MS), cinzas, proteína bruta (PB), fibra detergente neutra (FDN), fibra detergente ácido (FDA), DIVMS e DIVMO, em cada período. Os erros padrões das médias são apresentados entre parênteses.

Table 5 - Means of chemist quality of handplucking pasture, in percentage of: dry matter (DM), ash, crude protein (CP), NDF, ADF, in vitro digestibility of dry matter (IVDDM), in vitro digestibility of organic matter (IVDOM) for each period. Standart errors of the mean are shown in the brackets

\begin{tabular}{lccccccc}
\hline & \multicolumn{3}{c}{$\begin{array}{c}\text { Tratamentos } \\
\text { Treatments }\end{array}$} \\
\cline { 2 - 3 } $\begin{array}{l}\text { Atributos } \\
\text { Attributes }\end{array}$ & 0 & 0,75 & & \multicolumn{3}{c}{$\begin{array}{c}\text { Períodos } \\
\text { Periods }\end{array}$} \\
\hline MS (DM) & 25,50 & & 1,5 & & 1 & 2 & 3 \\
& $(1,03)$ & $(1,16)$ & $(1,28)$ & & $(1,10)$ & $(1,15)$ & $(1,78)$ \\
CINZAS (ASH) & 10,09 & 10,17 & 11,47 & & 12,70 & 9,82 & 9,21 \\
& $(0,25)$ & $(0,94)$ & $(2,15)$ & & $(1,57)$ & $(0,11)$ & $(0,46)$ \\
PB (CP) & 16,96 & 16,19 & 15,20 & & 14,44 & 16,95 & 16,96 \\
& $(0,42)$ & $(1,76)$ & $(0,77)$ & & $(1,27)$ & $(0,68)$ & $(0,68)$ \\
FDN (NDF) & 55,27 & 59,38 & 59,18 & & 54,56 & 57,22 & 61,55 \\
& $(1,64)$ & $(1,79)$ & $(3,22)$ & & $(1,94)$ & $(1,33)$ & $(1,96)$ \\
FDA (ADF) & 36,86 & 36,28 & 39,15 & & 37,96 & 35,99 & 38,34 \\
& $(1,19)$ & $(1,22)$ & $(0,52)$ & & $(0,38)$ & $(1,57)$ & $(1,12)$ \\
DIVMS (IVDDM) & 63,60 & 61,46 & 62,95 & & 59,82 & 63,63 & 64,56 \\
& $(2,55)$ & $(2,70)$ & $(2,70)$ & & $(2,96)$ & $(2,53)$ & $(3,02)$ \\
DIVMO (IVDOM) & 66,16 & 63,98 & 66,73 & & 64,54 & 66,06 & 66,27 \\
& $(3,24)$ & $(2,14)$ & $(2,14)$ & & $(2,34)$ & $(2,82)$ & $(3,43)$ \\
\hline
\end{tabular}

${ }^{1}$ T0 = controle; T0.75 = 0,75\% do peso vivo de sorgo moído; T1.5 = 1,5\% do peso vivo de sorgo moído.

TO = control; T0.75 $=0.75 \%$ of live weight of ground sorghum grain; T1.5 $=1.5 \%$ of live weight of ground sorghum grain .

valor crítico para GMD foi de $0,52 \mathrm{~kg} /$ dia com o fornecimento do suplemento na quantidade equivalente a 1,11\% do peso vivo dos animais, enquanto na média geral do experimento, o GMD crítico foi de $0,60 \mathrm{~kg}$ calculado para o fornecimento de suplemento na quantidade equivalente a $0,98 \%$ do PV.

A partir das informações apresentadas nas
Tabelas 3, 4, 5 e 6, pode-se inferir as possíveis causas que levaram os animais apresentarem um GMD crítico de $0,52 \mathrm{~kg}$ e os não suplementados ganharem $0,15 \mathrm{~kg} /$ dia, durante o primeiro período. O GMD do controle, de $0,150 \mathrm{~kg}$, é considerado normal em pastagem nativa nesta época, segundo Jacques (1999).

Entre as possíveis causas do ponto crítico para o

Tabela 6 - Médias e equações de regressão para ganho médio diário de peso (GMD, em kg) e incremento do escore de condição corporal (IECC) em função dos níveis de suplementação (X), em porcentagem do peso vivo) para cada período

Table 6 - Means and regression equations for average daily gain (ADG) ( $\mathrm{kg}$ ) and increment of body condition score (IBCC) related to energy supplement levels $(X)$ as live weight percentage at each experimental period

\begin{tabular}{|c|c|c|c|c|}
\hline \multirow[t]{2}{*}{$\begin{array}{l}\text { Períodos } \\
\text { Periods }\end{array}$} & \multicolumn{3}{|c|}{$\begin{array}{l}\text { Tratamentos } \\
\text { Treatments } \\
\end{array}$} & \multirow[t]{2}{*}{$\begin{array}{l}\text { Equações de regressão } \\
\text { Regression equations }\end{array}$} \\
\hline & $\mathrm{T} 0$ & $\mathrm{~T} 0.75$ & $\mathrm{~T} 1.5$ & \\
\hline 1 (11/08 a 06/09) GMD (ADG) & 0,15 & 0,48 & 0,48 & $\begin{array}{l}Y=0,15+0,66 x-0,29 x^{2} \\
P=0,0171\end{array}$ \\
\hline IECC(IBCC) & 0,00 & 0,35 & 0,42 & $\begin{array}{l}Y=0,88 x-0,433 x^{2} \\
P=0,0493\end{array}$ \\
\hline 2 (07/09 a 12/10) GMD (ADG) & 0,35 & 0,38 & 0,41 & $\mathrm{Y}=0,38$ \\
\hline IECC(IBCC) & 0,44 & 0,15 & 0,10 & $\mathrm{Y}=0,23$ \\
\hline 3 (13/10 a 14/11) GMD (ADG) & 0,86 & 0,92 & 0,79 & $\mathrm{Y}=0,85$ \\
\hline IECC(IBCC) & 0,31 & 0,15 & 0,40 & $Y=0,29$ \\
\hline Média (mean) GMD (ADG) & 0,45 & 0,59 & 0,56 & $\begin{array}{l}Y=0,45+0,31 x-0,16 x^{2} \\
P=0,0423\end{array}$ \\
\hline IECC(IBCC) & 0,25 & 0,24 & 0,28 & $Y=0,26$ \\
\hline
\end{tabular}

${ }^{1} \mathrm{T0}=$ controle; T0.75 = 0,75\% do peso vivo de sorgo moído; T1.5 = 1,5\% do peso vivo de sorgo moído.

$T O=$ control; $T 0.75=0.75 \%$ of live weight of ground sorghum grain; T1.5 $=1.5 \%$ of live weight of ground sorghum grain . 
Tabela 7 - Médias gerais de incremento de altura de cernelha $(\mathrm{cm})$ e perímetro torácico $(\mathrm{cm})$

Table 7 - Overall means of increase of height at withers $(\mathrm{cm})$ and, heart girth $(\mathrm{cm})$

\begin{tabular}{|c|c|c|c|c|}
\hline \multirow[t]{2}{*}{$\begin{array}{l}\text { Períodos } \\
\text { Periods }\end{array}$} & \multicolumn{3}{|c|}{$\begin{array}{c}\text { Tratamentos }^{1} \\
\text { Treatments }\end{array}$} & \multirow[t]{2}{*}{$\begin{array}{c}\text { Equações de regressão } \\
\text { Regression equations }\end{array}$} \\
\hline & T0 & T0.75 & T1.5 & \\
\hline $\begin{array}{l}\text { Ganho altura de cernelha } \\
\text { Increment of height } \\
\text { Ganho perímetro torácico } \\
\text { Increment of heart girth }\end{array}$ & 2,60 & 3,20 & 2,20 & $\begin{array}{c}Y=2,66 \\
P=0,8300 \\
Y=8,10 \\
P=0,3261\end{array}$ \\
\hline
\end{tabular}

${ }^{1}$ T0 = controle; T0.75 = 0,75\% do peso vivo de sorgo moído; T1.5 = 1,5\% do peso vivo de sorgo moído.

TO $=$ control; $T 0.75=0.75 \%$ of live weight of ground sorghum grain; T1.5 $=1.5 \%$ of live weight of ground sorghum grain .

GMD ser $1,11 \%$ do PV, pode-se citar a redução do consumo da forragem, devido ao efeito de substituição e à redução da digestibilidade ruminal da matéria seca ou da fibra. Segundo Caton \& Dhuyvetter (1997), em artigo de revisão sobre os efeitos da suplementação energética para ruminantes em pastejo, níveis moderados a altos de suplementos energéticos podem reduzir o consumo de forragem, ainda que o consumo de nutrientes digestíveis da dieta possa se manter ou mesmo aumentar. Além disso, os suplementos energéticos podem diminuir a digestibilidade ruminal da matéria seca ou mesmo da fibra, devido à diminuição do pH ruminal ou às relações desfavoráveis entre a energia e a proteína degradável. Os efeitos negativos sobre o consumo e a digestibilidade ruminal seriam notados, principalmente, com fornecimento de suplemento em nível igual ou superior a $0,8 \%$ do peso vivo ou $30 \mathrm{~g} / \mathrm{kg}$ de peso metabólico.

No presente trabalho, os níveis adotados de su- plemento de 0,75 e 1,5\% do peso vivo foram equivalentes a 27 e $52 \mathrm{~g} / \mathrm{kg}$ de peso metabólico, enquanto no nível crítico, a quantidade de suplemento foi equivalente a $40 \mathrm{~g} / \mathrm{kg}$ de peso metabólico. Estes resultados permitem inferir que o fornecimento de sorgo como suplemento energético acima de $40 \mathrm{~g} / \mathrm{kg}$ de peso metabólico exerceu efeitos adversos sobre o consumo e digestibilidade ruminal.

Restle et al. (1999) suplementaram novilhos de corte com grão de milho moído e não encontraram diferenças no GMD para os níveis de 0,5 e 1,0\% do peso vivo, e atribuíram este fato ao efeito de substituição de pastagem por suplemento. Frizzo et al. (2000) compararam níveis de 0, 0,7 e 1,4\% do peso vivo de uma mistura de farelo de arroz com polpa cítrica. Estes autores observaram aumento do ganho de peso vivo individual e por área (424, 563, 671 kg/ha, respectivamente) de novilhas da raça Charolês em comparação com aquelas não suplementadas, mas

Tabela 8 - Estimativas das exigências nutricionais dos animais, em kg por dia e como \% do consumo previsto, segundo NRC (1984) e das contribuições nutritivas do suplemento

Table 8 - Nutritional requirements estimated according to NRC (1984) and nutritive contributions from supplement

\begin{tabular}{|c|c|c|c|c|c|c|}
\hline & \multicolumn{3}{|c|}{$\begin{array}{c}\text { Período } 1 \\
\text { Periods } 1 \\
\text { GMD 0,4 kg }(A D G 0.4 \mathrm{~kg}) \\
\end{array}$} & \multicolumn{3}{|c|}{$\begin{array}{c}\text { Período } 3 \\
\text { Periods } 3 \\
\text { GMD 0,9 kg (ADG } 0.9 \mathrm{~kg})\end{array}$} \\
\hline & MS & PB & NDT & MS & PB & NDT \\
\hline & $D M$ & $C P$ & $T D N$ & $D M$ & $C P$ & $T D N$ \\
\hline \multicolumn{7}{|l|}{ Exigências ${ }^{1}$ (kg/dia e \% da MS) } \\
\hline Requirements ( $\mathrm{kg} /$ day and \% of DM) & 4,27 & $\begin{array}{r}0,46 \\
10,77\end{array}$ & $\begin{array}{c}2,5 \\
58,55\end{array}$ & 5,0 & $\begin{array}{c}0,64 \\
12,80\end{array}$ & $\begin{array}{l}3,38 \\
67,60\end{array}$ \\
\hline $\begin{array}{l}\text { Fornecido pelo suplemento }{ }^{1} \mathrm{~T} 0.75 \\
\text { Supplement contribution T0.75 }\end{array}$ & 1,15 & 0,09 & 0,86 & 1,27 & 0,332 & 0,97 \\
\hline $\begin{array}{l}\text { T0.75 (Exigência - Fornecido) } \\
\text { T0.75 (Requirements - Supplement) }\end{array}$ & 3,14 & 0,37 & 1,64 & 3,65 & 0,308 & 2,41 \\
\hline $\begin{array}{l}\text { Fornecido por suplemento }{ }^{1} \mathrm{~T} 1.5 \\
\text { Supplement contribution } T 1.5\end{array}$ & 2,26 & 0,18 & 1,72 & 2,54 & 0,433 & 1,93 \\
\hline $\begin{array}{l}\text { T1.5 (Exigência - Fornecido) } \\
\text { T1.5 (Requirements - Supplement) }\end{array}$ & 2,01 & 0,28 & 0,78 & 2,37 & 0,207 & 1,45 \\
\hline
\end{tabular}

${ }^{1}$ No período 3 , adicionaram-se $80 \mathrm{~g}$ de uréia ao sorgo.

${ }^{1}$ In the third period, $80 \mathrm{~g}$ of urea were added to sorghum. 
não observaram efeitos entre os níveis de suplementação. Rocha et al. (2000) observaram aumento do ganho de peso individual e por área em bezerras de corte suplementadas com sorgo fornecido em quantidade equivalente a $1,28 \%$ do seu peso vivo durante todo o ciclo da pastagem de azevém e aveia ou com 1,02\% de seu peso vivo em sorgo somente até outubro em relação aos animais não suplementados.

Contudo, Antunes et al. (2000) encontraram aumento crescente no ganho de peso de novilhos suplementados com 0, 0,75 e 1,5\% do peso vivo com grão de sorgo moído, respectivamente 0,36, 0,52 e $0,76 \mathrm{~kg} /$ dia. Estes autores mantiveram uma carga média de $1085 \mathrm{~kg}$ de peso vivo/ha e uma massa de forragem inicial e final de, respectivamente, 3120 e $1453 \mathrm{~kg}$ de matéria seca/ha.

O efeito negativo de doses altas de amido sobre a digestibilidade da fibra da forragem foi verificado por Garcés-Yepez et al. (1997), Ferrel et al. (1999) e Philippeau et al. (1999) que encontraram que doses altas de amido (25 e 50\% da exigência de NDT) exerceram efeitos associativos negativos sobre a digestão, provocado pelas mudanças no ecossistema ruminal.

Galloway et al. (1993) encontraram o mesmo efeito depressor do amido sobre a digestão da fibra no inverno e no verão, quando o suplemento energético foi dado em doses superiores a $0,5 \%$ do peso vivo, a animais consumindo feno de Dactylis glomerata. Segundo Hoover (1986), em pastagens de baixa qualidade, doses de grãos maiores que $30 \%$ da MS consumida podem diminuir a digestibilidade da fibra. Entretanto, em pastagem de alta qualidade, este decréscimo na digestibilidade da fibra não foi observada por Elizalde et al.(1999), que suplementaram novilhos em pastagem de alfafa e encontraram uma resposta linear entre o consumo de milho e o consumo de forragem.

Apesar de a forragem aparentemente consumida apresentar teores de proteína bruta e digestibilidade bastante razoáveis (Tabela 5), a grande quantidade de material morto (Tabela 4) provavelmente aumentou o tempo de procura e seleção da forragem dos animais não suplementados, com reflexos negativos sobre o consumo de forragem.

No segundo período de avaliação, não houve efeito da suplementação sobre o GMD (P>0,05). Notou-se uma diminuição dos valores numéricos do GMD nos grupos suplementados com relação ao período inicial (Tabela 6). A quantidade de matéria seca de forragem por hectare foi superior em relação ao primeiro período (Tabela 3), mas houve alagamento de boa parte dos potreiros devido à elevada precipitação (241 mm, Tabela 1). Isto pode ter causado diminuição do consumo de pasto.

Estes fatos mais a diminuição do consumo da forragem, devido à substituição pelo sorgo, e possivelmente a ação do amido do grão sobre a digestibilidade da fibra da pastagem, podem ter causado uma resposta nula do suplemento sobre o GMD (Tabela 6). O controle, neste período, pode ter sido favorecido pelo pequeno aumento na disponibilidade de MS com relação ao período 1 e pela oferta de pastejo favorável (27,04 kg de MS/100 kg de peso vivo).

Pode ser observado que, no grupo controle, se trabalhou com uma carga média 17\% menor em comparação aos animais suplementados (Tabela 3). Rocha (1999) salienta que uma das maiores vantagens da suplementação é a possibilidade de se aumentar a carga animal e, com isto, a produção de carne por área. Autores como Rocha et al. (2000) e Frizzo et al. (2000) trabalharam com cargas 30 a $40 \%$ superiores, em pastagens cultivadas de inverno, nos tratamentos com suplementação em relação aos não suplementados.

No período 3, com a melhora na proporção de material verde disponível da pastagem, e aumentos nos teores de $\mathrm{PB}$ e aumento da digestibilidade in vitro da matéria seca e orgânica (Tabela 5), os animais controle apresentaram um GMD de 0,858 kg, considerado ganho possível em pastagem natural na primavera-verão (Jacques, 1999). Os GMD dos animais suplementados não foram diferentes do controle nem entre níveis de suplementação.

Neste período, considerando a composição química da forragem coletada por simulação de pastejo (Tabela 5) e as exigências nutricionais para animais de $180 \mathrm{~kg}$ de peso vivo (Tabela 8), observa-se que a pastagem permitiu adequado aporte de nutrientes para GMD de 0,9 kg. A composição química da pastagem aparentemente consumida forneceu em média valor de $17 \%$ de proteína bruta e digestibilidade da matéria seca em torno 64,5\% (Tabela 5), o que atende às exigências nutricionais dos animais para os ganhos de peso esperados (Tabela 8). Nesse período, o efeito da suplementação pode ter sido basicamente substitutivo.

Foi realizada a estrutura de custos de produção por hectare considerando um período total de 90 dias, animais com peso inicial de $160 \mathrm{~kg}$, as cargas médias praticadas nos três períodos, que foram de 336,2, 
Tabela 9 - Custos de produção por ha, considerando o GMD obtidos nos 3 períodos, a carga animal média praticada e novihos com peso vivo inicial de $160 \mathrm{~kg}$, num período de 90 dias, valores em US $\$ 2$

Table 9 - Production cost per ha, considering ADG at the 3 periods, mean stockin rate and a steer with $160 \mathrm{~kg}$ inicial body weight over a period of 90 days, values as US\$2

\begin{tabular}{|c|c|c|c|}
\hline \multirow[t]{2}{*}{$\begin{array}{l}\text { Item } \\
\text { Item }\end{array}$} & \multicolumn{3}{|c|}{$\begin{array}{c}\text { Tratamento }^{1} \\
\text { Treatment }^{1}\end{array}$} \\
\hline & T0 & T0.75 & T1.5 \\
\hline Animal (Steer)160 kg & 188,76 & 220,22 & 220,22 \\
\hline Ração (Supplement) & 0,00 & 19,66 & 38,02 \\
\hline Frete (Transport)1,344 & 1,57 & 1,59 & \\
\hline Mantença cerca (Maintainance of fence) & 0,432 & 0,504 & 0,5 \\
\hline Medicamentos (Medicament) & 3,912 & 4,56 & 4,56 \\
\hline Sal mineral (Mineral salt) & 6,58 & 7,67 & 7,67 \\
\hline Mão de obra (Manual job) & 1,752 & 2,44 & 2,85 \\
\hline Arrendamento de pasto (Renting tenure) & 2,52 & 2,52 & 2,52 \\
\hline Outros (Others) & 4,53 & 5,79 & 6,27 \\
\hline Total (Total) & 209,83 & 264,93 & 284,2 \\
\hline Venda (Sale) & 529,58 & 657,44 & 647,74 \\
\hline Diferença (Diference) & 319,75 & 392,51 & 363,54 \\
\hline
\end{tabular}

1 T0 = controle; T0.75 = 0,75\% do peso vivo de sorgo moído; T1.5 = 1,5\% do peso vivo de sorgo moído.

TO = control; TO.75 $=0,75 \%$ of live weight of ground sorghum grain; T1.5 $=1,5 \%$ of live weight of ground sorghum grain .

2 US\$1 = R $\$ 2,38$, junho de 2001 (US\$1 = R $\$ 2.38$, June 2001).

389,7 e 393,6 kg/ha para o controle e níveis de suplementação 0,75 e 1,5\% do peso vivo, respectivamente, e o GMD encontrado para cada tratamento, com médias de 0,451,0,594e 0,559kg, para o controlee níveis de suplementação 0,75 e 1,5\% do peso vivo (Tabela 9).

O T0.75\% apresentou o maior ganho econômico, $22,5 \%$ superior ao controle e $7,97 \%$ superior ao nível 1,5\% de suplementação.

Estes ganhos são reflexo da maior carga praticada nos lotes suplementados durante o período experimental e do maior GMD encontrado no periodo 1, para os animais suplementados.

Rocha et al. (2001), ao estudarem a viabilidade econômica da prática da suplementação de pastagens cultivadas de aveia e azevém, verificaram que o controle e o nível intermediário de suplementação ( $0,7 \%$ do peso vivo) permitiram as maiores margens, enquanto o nível alto de suplementação $(1,4 \%$ do peso vivo) permitiu uma margem muito menor, respectivamente 135,13, 136,33 e 22,30 equivalentes de kg de boi gordo na região de Santa Maria (RS), ainda que o ganho de peso vivo por área dos animais suplementados tenha sido bem maior, de 424, 536 e $671 \mathrm{~kg} / \mathrm{ha}$, respectivamente para os níveis $0,0,7$ e $1,4 \%$ do peso vivo de uma mistura de $50 \%$ farelo de arroz e 50\% polpa cítrica.

Embora a análise estatística dos atributos da pastagem não tenha sido possível, constatou-se que, nos potreiros onde foi fornecido o suplemento, houve aumento da quantidade de forragem residual (Tabela 3). O potreiro, onde os animais receberam $\mathrm{T} 1.5 \%$ apresentou o maior valor da porcentagem de material morto (Tabela 4). Estes fatos podem estar relacionados com o provável menor consumo de forragem pelos animais suplementados, especialmente os do T1.5\%. A suplementação pode ter exercido efeito sobre a composição florística da pastagem, tendo em vista a alteração dos valores numéricos (Tabela 4). A participação de Eragrostis planna aumentou do controle para o nível de 1,5\%, enquanto a participação de Paspalum sp. + Axonopus sp. diminuiu. Este fato pode estar relacionado com modificações na atividade de pastejo e seletividade exercida pelos animais. Segundo Pardo (2001), que estudou o comportamento ingestivo dos animais utilizados neste experimento, o tempo diurno de pastejo destes animais decresceu à medida que os níveis de suplementação aumentaram, passando, no primeiro período, de 382 minutos para 335 e 289 minutos, respectivamente, para os tratamentos controle, T0,75 e T1,5\%. Notou-se a maior presença de animais em pastejo sempre para o controle, e a menor atividade foi observada para o nível maior de suplementação. As percentagens do tempo diurno de pastejo com relação ao tempo avaliado foram de 66,2; 48,16 e $43,75 \%$, respectivamente para os grupos controle, suplementados a 0,75 e $1,5 \%$ do peso vivo. 


\section{Conclusões}

A suplementação energética aumentou o GMD e o IECC de animais em pastagem nativa melhorada e invadida por capim-anonni 2, apenas no período do final de inverno.

Entre os três níveis de suplementação avaliados neste estudo, os melhores índices econômicos foram observados para o nível 0,75\%.

Não houve efeito dos níveis de suplemento sobre os ganhos de altura e perímetro torácico.

\section{Literatura Citada}

ABDALLA, H.O.; FOX, D.G.; SEANEY, R.R., et al. Variation in protein and fibers fractions in pasture during the grazing season. Journal of Animal Science, v.66, n.10, p.26632667, 1988.

ANTUNES, V.S.; FISCHER, V.; MORENO, C.B. et al. Efeitos de níveis crescentes de suplemento energético sobre o desempenho de bezerros de corte em pastejo. In: REUNIÃO ANUAL DA SOCIEDADE BRASILEIRA DE ZOOTECNIA, 37., 2000, Viçosa, MG. Anais ... Viçosa: Sociedade Brasileira de Zootecnia, 2000. p. 433.

ASSOCIATION OF OFFICIAL ANALITICAL CHEMIST AOAC. Official methods of analysis. 12.ed. Washington, D.C.: 1975. 1094p.

BOIN, C.; TEDESCHI, LO. Sistemas intensivos de produção de carne bovina: II. Crescimento e acabado. In: PEIXOTO, A.M. (Ed.). Produção de novilhos de corte. Piracicaba: Fundação de Estudos Agrários "Luiz de Queiroz", 1996. p.205-225.

CATON, J.S.; DHUYVETTER, D.V. Influence of energy supplementation on grazing ruminants: requirements and responses. Journal of Animal Science, v.75, p.533-542, 1997.

CORREA, F.L. Produção e qualidade de uma pastagem nativa sob níveis de oferta de pastagem a novilhos. Porto Alegre: Universidade Federal de Rio Grande do Sul, 1993. 167p. Dissertação (Mestrado em Zootecnia) - Universidade Federal de Rio Grande do Sul, 1993.

ELIZALDE, J.C.; MERCHEN, N.R.; FOULKNER, D.B. Supplemental cracked corn for steers fed fresh alfalfa: I. Effects on digestion of organic matter fiber and starch. Journal of Animal Science, v.77, n.2, p.457-466, 1999.

FERREL, C.L.; KREIKEMEIER, J.; FREETLY, H.C. The effect of supplemental energy, nitrogen and protein on feed intake, digestibility and nitrogen flux across the gut and liver in sheep fed low-quality forage. Journal of Animal Science, v.77, n.12, p.3353-3364, 1999.

FRIZZO, A.; ROCHA, M.G.; RESTLE, J. et al. Efeito de diferentes níveis de suplementação energética no desempenho de bezerras em pastejo. In: REUNIÃO ANUAL DA SOCIEDADE BRASILEIRA DE ZOOTECNIA, 37., 2000, Viçosa, MG. Anais ... Viçosa, MG: Sociedade Brasileira de Zootecnia, 2000. p.84.

GALLOWAY, D.L.; GOETSCH, A.L.; FORSTER Jr., L.A. Feed intake and digestibility by cattle consuming bermuda grass or orchard grass hay supplemented with soybean hulls and corn. Journal of Animal Science, v.71, n.11, p.3087-3095, 1993.
GARCÉS-YEPEZ, P.; KUNKLE, W.E.; BOITES, D.B. Effects of supplemental energy source and amount of forage intake and performance by steers and intake and diet digestibility by sheep. Journal of Animal Science, v.75, n.7, p.1918-1925, 1997.

GARDNER, A.L. Técnicas de pesquisa em pastagens e aplicabilidade de resultados en sistemas de produção. Brasil: IICA, 1986. 197p.

GOERING, H.K.; Van SOEST, P.J. Forage fiber analysis (apparatus, reagents, procedures and some aplications). Agriculture Handbook, n.379. Agriculture Research Service. US Department of Agriculture. Washington, D.C., 1970.

HAYDOCK, K.P.; SHAW, N.G. The comparative yield method for estimating dry matter yield of pasture. Australian Journal of Experimental Agriculture Animal Husbandry, v.15, p.663-670, 1975.

HODGSON, J. Grazing management: science into practice. London: Longman Scientific \& Technical, 1990. 203p.

HOOVER, W.H. Chemical factors involved in ruminal fiber digestion. Journal of Dairy Science, v.69, n.10, p.27552766, 1986.

HORN, G.W.; CRAVEY., M.D.; McCOLLUM, F.T. et al. Influence of high starch vs high-fiber energy supplements on performance of stocker cattle grazing wheat pasture and subsequent feedlot performance. Journal of Animal Science, v.73, n.1, p.45-54, 1995.

IBGE. 1998. Censo Agropecuário 1995-96. Rio de Janeiro. 366p.

JACQUES, A.V.A. Qualidade da pastagem nativa. In: FEDERACITE VIII, CADEIAS FORRAGEIRAS REGIONAIS, 1999. Porto Alegre, p.117.

JACQUES, A.V.A.; SAIBRO, J.C.; LOBATO, J.F.P. et al. Sistemas de produção de forragens para a Depressão Central/ RS. In: FEDERACITE IV, Cadeias forrageiras regionais. Porto Alegre, 1995. p.13-28.

MOHRDIECK, K.H. Formações campestres do Rio Grande do Sul. In: SEMINÁRIO SOBRE PASTAGENS 'DE QUE PASTAGENS NECESSITAMOS”, 1980, Porto Alegre. Anais...Porto Alegre: FARSUL, 1980. p.18-27.

MOOJEN, E.L. Dinâmica e potencial produtivo de uma pastagem nativa do Rio Grande do Sul submetida a pressões de pastejo, época de diferimento e níveis de adubação. Porto Alegre: Universidade Federal de Rio Grande do Sul, 1991. 231p. Tese (Doutorado em Zootecnia) Universidade Federal de Rio Grande do Sul, 1991.

NATIONAL RESEARCH COUNCIL - NRC. Nutrient requirements of beef cattle. 6.ed. Washington, D.C.: National Academic Press, 1984. 90p.

PARDO, R.M.P. Efeitos de níveis crescentes de suplemento energético em bezerros de corte em pastejo. Pelotas: Universidade Federal de Pelotas, 2001. 81p. Dissertação (Mestrado em Zootecnia) - Universidade Federal de Pelotas, 2001.

PHILIPPEAU, C.; MARTIN, C.; MICHALET-DOREAU, B. Influence of grain source on ruminal caracteristics and rate, site and extent of digestion in beef steers. Journal of Animal Science, v.77, n.6, p.587-1596, 1999.

POPPI, D.P.; HUGHES, T.P.; L'HUILLIER, P.J. Intake of pasture by grazing ruminants. In: NICOL, A.M. (ed.). Livestock production feeding on pasture. Nova Zelândia: New Zealand Society of Animal Production. Occasional Publication n.10, 1987. p.55-63.

REIS, R.A.; RODRIGUES, L.R.; PEREIRA, J.R. A suplementação como estratégia de manejo da pastagem. In: PEIXOTO, A. (Ed.). Produção de bovinos a pasto. Piracicaba: Fundação de 
Estudos Agrários "Luiz de Queiroz" 1999. p.123-150.

RESTLE, J.; BACK, M.; BRONDANI, I. et al. Suplementação associada com lasalocid para novilhos em terminação em pastagem cultivada de inverno. Ciência Rural, v.29, n.3, p.555-559, 1999.

ROCHA, M.G. Suplementação a campo de bovinos de corte. In: LOBATO, J.F. (Ed.). Produção de bovinos de corte. Porto Alegre: PUCRS, 1999. p.77-96.

ROCHA, M.G.; RESTLE J.; FARINATTI, L.H. et al. Efeito da suplementação energética sobre a produção animal em pastagem cultivada de inverno. In: REUNIÃO ANUAL DA SOCIEDADE BRASILEIRA DE ZOOTECNIA, 37., 2000, Viçosa, MG. Anais ... Viçosa: Sociedade Brasileira de Zootecnia, 2000. p.82.

ROCHA, M.G.; PILAU, A.; SANTOS, D.T. et al. Produção animal e retorno econômico da suplementação energética em pastagem cultivada de inverno. In: REUNIÃO ANUAL DA SOCIEDADE BRASILEIRA DE ZOOTECNIA, 38., 2001, Piracicaba. Anais ... Piracicaba: Sociedade Brasileira de Zootecnia, 2000. p. 198.

STATISTICAL ANALYSIS SYSTEM - SAS. Version for WINRelease 6.11. Cary, NC, USA. 1989-1995.
STOBBS, T.H. The effect of plant structure on the intake of tropical pastures. III. Influence of fertilizer nitrogen on the variation in the bite size of bite harvested by jersey cows grazing Setaria anceps cv Kazungula swards. Australian Journal of Agricultural Research, v.26, p.997-1007, 1975.

TEDESCO, M.J.; GIANELLO, C.; BISSARI, C.A. et al. Análise de solo, plantas e outros materiais. Porto Alegre: Universidade Federal do Rio Grande do Sul, 1995. 174p. (Boletim técnico)

TILLEY, J.M.; TERRY, R.A. A two-stage technique for the in vitro digestion of forage crops. Journal of British Grassland Society, v.18, n.2, p.104-111, 1963.

Van SOEST, P.J. Nutritional ecology of the ruminant. 2.ed. Ithaca \& London: Cornell University Press, 1994. 476p.

WALKER, J.W. Viewpoint: grazing management and research now and in the next millenium. Journal of Range Management, v.48, n.4, p.350-357, 1995.

Recebido em: 21/01/02 Aceito em: 24/02/03 